\title{
БИОСИСТЕМНАЯ САМООРГАНИЗАЦИЯ И ФРАКТАЛЬНАЯ СТРУКТУРА ЧАСТОТНО-ТАКСОНОМИЧЕСКИХ ПРОФИЛЕЙ МИКРОБИОТЫ КИШЕЧНИКА БРОЙЛЕРОВ ПОД ВЛИЯНИЕМ КОРМОВЫХ ПРОБИОТИКОВ
}

\author{
Н.И. ВОРОБЬЕВ ${ }^{1}$, И.А. ЕГОРОВ 2 , И.И. КОЧИШ ${ }^{3}$, И.Н. НИКОНОВ 3 , \\ Т.Н. ЛЕНКОВА
}

В статье приводятся теоретические и эмпирические данные о влиянии пробиотиков на биоконсолидацию микробиоты кишечника бройлеров кросса Смена. Результаты таких исследований могут быть использованы для повышения качества и объемов мясной продукции при крупномасштабном производстве. Пробиотики использовались для улучшения усвояемости кормов и ускорения развития птицы. Для стимуляции процессов трансформации растительных субстратов в кишечнике птиц вместо антибиотиков применяли пробиотики. Пробиотики содержали бактерии Lactobacillus plantarum и Lactobacillus fermentum. Цель исследования заключалась в разработке методики фрактального анализа частотно-таксономических профилей оперативно-таксономических единиц (ОТЕ) микробиоты кишечника у птиц. С использованием фрактальной методики вычислялся индекс биоконсолидации кишечной микробиты, который характеризует биосистемную самоорганизацию микрофлоры и эффективность биохимических преобразований растительных субстратов в кишечнике птицы. В опыте исследовалась микрофлора у одной контрольной и двух опытных групा птицы. Профили ОТЕ были получены молекулярно-генетическим методом NGS (Next Generation Sequencing). Понятие элементарного фрактала ОТЕ было принято в качестве ключевого для фрактального анализа профилей ОТЕ. Элементарный фрактал ОТЕ - это три ОТЕ, частоты которых образуют геометрическую числовую последовательность, например $\{0,5 ; 0,25 ; 0,125\}$. Профили ОТЕ могут содержать несколько элементарных фракталов ОТЕ, объединенных в один более крупный мегафрактал ОТЕ. Мы предполагаем, что если увеличивается число ОТЕ, объединенных в мегафрактал ОТЕ, то эффективнее и в больших масштабах осуществляются биохимические преобразования растительного субстрата и макроорганизм получает больше питательных веществ. Поэтому индекс биоконсолидации микробиоты бройлеров мы определяем, как отношение числа ОТЕ в составе мегафрактала ОТЕ к общему числу ОТЕ в профилях ОТЕ. Для выделения элементарных фракталов ОТЕ использовались фрактальные портреты профилей ОТЕ. Идентификация элементарных ОТЕ фракталов осуществлялась по линейному расположению трех изображений ОТЕ на фрактальных портретах. Фрактальный анализ подтвердил, что бактериальные пробиотики увеличивают биоконсолидацию микробиоты в кишечнике птиц. Индекс биоконсолидации микробиоты у птиц из опытных групп $(0,82 \ldots 0,86)$ был выше, чем у контрольной группы $(0,55)$. По результатам фрактального анализа не рекомендован к применению пробиотик № 1 (с Lactobacillus plantarum) и рекомендован к применению пробиотик № 2 (c Lactobacillus fermentum).

Ключевые слова: частотно-таксономический профиль, фрактальный портрет, микробиота кишечника, индекс биосистемной консолидации микробиоты, бройлеры, кормовые пробиотики, Lactobacillus.

В Российскую Федерацию ежегодно импортируется большое количество племенного и гибридного молодняка птицы, что становится причиной неконтролируемого распространения возбудителей инфекционных болезней различной этиологии. В связи с этим в последние несколько лет активно ведутся исследования по замещению импортируемых кур отечественными высокопродуктивными кроссами, маркированными генами медленной и быстрой оперяемости. При этом особое внимание уделяется рационам птиц и условиям содержания, а также изучению реакций микробиома птиц на отдельные компоненты кормов, так как при крупномасштабном производстве

\footnotetext{
* Исследование выполнено на базе ФНЦ «ВНИТИП» РАН при поддержке гранта РНФ для реализации научного проекта 16-16-04089-П «Изучение физиологических и микробиологических особенностей пищеварения кур мясных пород в эмбриональный и постэмбриональный периоды для создания новых технологий кормления, обеспечивающих максимально полную реализацию генетического потенциала птицы».
} 
результаты таких исследований значительно повышают качество и объемы производимой мясной продукции.

Усвояемость кормов птицей целиком зависит от ферментативной преобразовательной деятельности кишечной микробиоты (1-4). При изменении условий содержания, рационов, использовании кормовых антибиотиков, про- и пребиотиков (5-8) и контаминации кормов микотоксинами (9-11) микробиота, колонизирующая пищеварительный тракт птицы, вынуждена перестраивать деструктивные биосистемы, меняя численность и состав биосистемных генотипов. В результате перестроек микробиоты кишечника птиц удается поддерживать на максимально эффективном уровне биотрансформацию растительных субстратов разного генезиса (12). Это позволяет перенаправлять большую часть питательных ресурсов на развитие птицы.

Биосистемная самоорганизация микробных сообществ в кишечнике птицы необходима не только для трансформации субстратов в питательные вещества, но и для своевременной доставки макроорганизму всех необходимых питательных веществ. Следовательно, птицы при наличии микробной биосистемы в кишечнике должны быстрее набирать живую массу и демонстрировать максимальную яйценоскость. Кроме этого, микробные биосистемы могут выполнять защитные функции против посторонней патогенной микрофлоры (13). Таким образом, биосистемная самоорганизация микробных сообществ в кишечниках птиц может рассматриваться как благоприятный компонент физиологического состояния птиц, обеспечивающий их полноценное развитие и высокую яйценоскость.

Макроорганизм и микробиота кишечника птицы образуют целостную биосистему, в которой они взаимодействуют и решают сообща задачи развития и выживания. При изменении состава кормов микробная биосистема в кишечнике птицы перестраивается, меняя свою конфигурацию и состав микробных генотипов, чтобы максимально эффективно трансформировать разнообразные растительные субстраты в питательные вещества (14-16). В связи с этим частичное или полное участие генотипов микробиома в биосистемных процессах может рассматриваться как количественный показатель интенсивности и эффективности биохимических преобразований растительных субстратов в кишечнике птицы и как уровень ее защищенности от патогенной микрофлоры (17-19).

В биосистему встраивается только часть микробиоты кишечника птиц. При самоорганизации биосистем из микробиоты выбираются только те генотипы, которые наиболее эффективно и с наименьшими энергетическими и ресурсными затратами способны выполнять требуемые биохимические преобразования кормовых субстратов $(4,18,19)$. Поэтому, биосистемная организация и биоконсолидация микроорганизмов обеспечивают выполнение всех требуемых биохимических преобразований органических субстратов с максимальной интенсивностью и в определенной последовательности, то есть организованно, поэтапно и с наименьшими энергетическими и ресурсными затратами со стороны макроорганизма. В таких условиях птица в полном объеме получает все необходимые питательные вещества и ускоренно развивается.

При смене кормового рациона микробная биосистема кишечника птиц автоматически перестраивается, меняя состав генотипов, ферментативные синтетические схемы и межкомпонентные биосистемные связи (3, 13). Для стимулирования преобразующей деятельности микробных биосистем и повышения эффективности процессов трансформации растительных 
субстратов в кишечнике птиц применяются различные кормовые добавки: антибиотики, экзогенные ферменты, пребиотики, пробиотики, синбиотики, фитобиотики (4). Однако обнаруженная у патогенных микроорганизмов способность адаптации к антибиотикам и приобретения ими антибиотикорезистентности (20) привела к тому, что в странах ЕС с 2006 года введен запрет на их использование антибиотиков в кормах для птицы. В связи с этим актуальными становится применение иных видов кормовых стимулирующих и защитных добавок, замещающих антибиотики (6).

Современные молекулярно-генетические методы позволяют получать объемную и детальную молекулярно-генетическую информацию о микробиоте кишечника птиц. В результате становятся доступными подробные частотно-таксономические профили оперативно-таксономических единиц (профили ОТЕ), насчитывающие тысячи ОТЕ (21). По гену 16S pPHK удается получать профили ОТЕ, среди которых только у $10 \%$ идентифицируется по международным таксономическим информационным базам род и вид, а в остальных случаях ОТЕ пополняют список неидентифицированных генотипов, представляющих, возможно, новые виды и роды (21-23). Профили ОТЕ содержат в себе не только таксономическую информацию о культивируемых и некультивируемых представителях микробиоты кишечника птицы, но и количественные данные по каждому микробному генотипу, начиная с минорных и кончая мажорными представителями кишечной микробиоты. Для многомерного статистического анализа количественной и таксономической информации профиля ОТЕ наилучшим образом подходит фрактальный анализ.

Фрактальный анализ биологических данных относится к классу многомерных статистических анализов. Поэтому с его помощью из всей совокупности фактических молекулярно-генетических данных удается извлекать сведения об особенностях биосистемной организации микробиомов птиц и изучать влияние пробиотиков на самоорганизацию микробных биосистем. В приложении к профилям ОТЕ ключевым понятием фрактального анализа является понятие элементарного фрактала ОТЕ, учитывающее особое степенное соотношение частот трех ОТЕ $(24,25)$. Это ключевое понятие проистекает из фундаментальных степенных количественных соотношений, которые находят свое отражение в относительных размерах элементов у всех объектов природы, в том числе у растений (например, фракталы деревьев) и у микробиологических биосистем.

Очевидно, что любые изменения в рационах кормления и содержания птиц находят свое отражение в изменениях профилей ОТЕ и их фрактальных характеристик. Мы полагаем, что снижение количества элементарных фракталов ОТЕ и числа микробных генотипов во фракталах ОТЕ является признаком ослабления биосистемных взаимодействий микроорганизмов и снижения производительности осуществляемых биохимических преобразований. Поэтому, используя фрактальный анализ частотно-таксономических профилей ОТЕ и определяя индекс биоконсолидации микробиоты кишечника птиц, можно будет оценивать влияние пробиотиков на биосистемную самоорганизацию микробных сообществ и на динамику развития птицы.

Цель исследования заключалась в разработке методики фрактального анализа частотно-таксономических профилей оперативных таксономических единиц (ОТЕ) микробиоты кишечника птиц. Фрактальная методика позволит вычислять индекс биоконсолидации микробиоты кишечника птиц, а индекс биоконсолидации, в свою очередь, предполагается исполь- 
зовать для изучения влияния пробиотиков на биосистемную самоорганизацию микрофлоры и эффективность биохимических преобразований растительных субстратов в кишечнике птиц.

Описание методики. Материалы и методики верификационного эксперимента. Для верификации методики фрактального анализа профилей ОТЕ был проведен научно-производственный опыт в СГЦ «Загорское ЭПХ» (Московская обл., 2018 год) с тремя группами цыплят-бройлеров кросса Смена (по 25 гол. в группе). В эксперименте цыплят содержали в клеточных батареях AviMax («Big Dutchman», Германия). Птицу выращивали до 36-суточного возраста в соответствии с рекомендованными нормами кормления и содержания (ФНЦ ВНИТИП РАН). Птица контрольной группы (1к) получала основной рацион (ОР, табл. 1), в опытной группе (2о) к ОР добавляли пробиотик № 1, содержащий Lactobacillus plantarum $\left(10^{7} \mathrm{KOE} / г\right)$, в дозе 1 кг/т корма, в опытной группе (3о) к ОР добавляли пробиотик № 2, содержащий Lactobacillus fermentum $\left(10^{7} \mathrm{KOE} / г\right)$, в дозе 1 кг/т корма.

1. Состав (\%) основного рациона (ОР) по группам цыплят-бройлеров кросса Смена, получавших экспериментальные пробиотические препараты $(n=25$, СГЦ «Загорское ЭПХ», Московская обл., 2018 год)

\begin{tabular}{|c|c|c|c|c|c|c|}
\hline \multirow{3}{*}{ Ингредиент } & \multicolumn{6}{|c|}{ Период выращивания, сут } \\
\hline & \multicolumn{3}{|c|}{$1-21-\mathrm{e}$} & \multicolumn{3}{|c|}{$22-36-\mathrm{e}$} \\
\hline & $1 \mathrm{~K}$ & 20 & 30 & $1 \mathrm{~K}$ & 20 & 30 \\
\hline Кукуруза & 60,00 & - & - & 60,00 & - & - \\
\hline Пшеница & - & 63,58 & 65,59 & - & 60,00 & 61,92 \\
\hline Соевый шрот & 26,21 & 16,63 & 16,52 & 17,12 & 17,52 & 17,43 \\
\hline Кукурузный глютен & 3,50 & 7,17 & 6,87 & 7,52 & 5,44 & 5,18 \\
\hline Мука рыбная & 4,59 & 4,00 & 4,00 & - & - & - \\
\hline Шрот подсолнечный & - & - & - & 6,98 & 4,92 & 4,86 \\
\hline Масло подсолнечное & 2,00 & 4,46 & 2,76 & 3,83 & 7,53 & 5,92 \\
\hline Известняк & 1,46 & 1,58 & 1,58 & 1,49 & 1,53 & 1,53 \\
\hline Монокальцийфосфат & 0,91 & 0,82 & 0,82 & 1,35 & 1,23 & 1,23 \\
\hline Монохлоргидрат лизина & 0,23 & 0,50 & 0,50 & 0,50 & 0,50 & 0,50 \\
\hline DL-метионин & 0,29 & 0,31 & 0,31 & 0,25 & 0,30 & 0,30 \\
\hline Треонин & 0,09 & 0,17 & 0,17 & 0,12 & 0,15 & 0,15 \\
\hline Соль & 0,22 & 0,28 & 0,28 & 0,34 & 0,38 & 0,38 \\
\hline Целлобактерин-Т & - & - & 0,10 & - & - & 0,10 \\
\hline Премикс & 0,50 & 0,50 & 0,50 & 0,50 & 0,50 & 0,50 \\
\hline \multicolumn{7}{|c|}{$\begin{array}{l}\text { П р и м е ч а н и е. } 1 \text { к - контрольная, } 20 \text {, 3о - две опытные группы бройлеров. В группе 2о к ОР добавляли } \\
\text { пробиотик № } 1 \text {, содержащий Lactobacillus plantarum }\left(10^{7} \mathrm{KOE} / \Gamma\right) \text {, в 3о - пробиотик № } 2 \text {, содержащий Lac- } \\
\text { tobacillus fermentum }\left(10^{7} \mathrm{KOE} / \text { г) (дозы препаратов }-1 \text { кг/т корма). Прочерки означают, что соответствую- }\right. \\
\text { щий ингредиент из рациона исключали. }\end{array}$} \\
\hline
\end{tabular}

По окончании опыта (на 36-е сут) бройлеров взвешивали. Статистическую обработку результатов проводили стандартными методами дисперсионного анализа с использованием программного обеспечения Microsoft Excel 2010. Применяли параметрические ( $t$-критерий Стьюдента) и непараметрические (метод Вилкоксона-Манна-Уитни) методы статистики. Определяли средние значения $(M)$ и стандартные ошибки средних $( \pm \mathrm{SEM})$.

Пробы содержимого слепых отростков кишечника отбирали после убоя цыплят в 36-суточном возрасте по три повторности из каждой группы со строгим соблюдением правил асептики и методики отбора проб и немедленно замораживали. Микробиоту содержимого слепых отростков исследовали методом NGS (next generation sequencing) (26) на базе Международной лаборатории молекулярной генетики и геномики птицы (г. Москва). Для выделения тотальной ДНК использовали набор Genomic DNA Purification Kit («Fermentas, Inc.», Литва). ПЦР проводили с эубактериальными праймерами 343F (5'-CTCCTACGGRRSGCAGCAG-3') и 806R (5'-GGACTACNVGGGTWTCTAAT-3') (ДНК-амплификатор Verity, «Life 
Technologies, Inc.», США). Выполняли метагеномное секвенирование амплифицированных фрагментов гена 16S pPHK (MiSeq Reagent Kit v3, установка MiSeq «Illumina, Inc.», США). Полученные риды подвергали биоинформационной обработке (платформа CLC Bio GW 7.0, «Qiagen N.V.», Нидерланды). Таксономический анализ проводили с помощью программы RDP Classifier (https://rdp.cme.msu.edu/classifier/classifier.jsp), используя информационные базы данных.

2. Таксономические группы микроорганизмов в частотно-таксономических профилях ОТЕ микробиоты кишечника у 36-суточных цыплят-бройлеров кросса Смена, получавших экспериментальные пробиотические препараты $(n=25$, СГЦ «Загорское ЭПХ», Московская обл., 2018 год)

\begin{tabular}{cl}
\hline № OTE & \multicolumn{1}{c}{ Группа микроорганизмов } \\
\hline 1 & Бациллы \\
2 & Лактобациллы* \\
4 & Бифидобактерии \\
5 & Целлюлозолитики. Лахноспиры \\
6 & Целлюлозолитики. Руминококки \\
7 & Целлюлозолитики. Клостридии \\
8 & Целлюлозолитики. Бактероиды \\
9 & Целлюлозолитики. Эубактерии \\
10 & Условно патогенные. Энтеробактерин* \\
1 & Условно патогенные. Актиномицеты* \\
13 & Стафилококки \\
14 & Кампилобактер \\
15 & Псевдомонады \\
16 & Протеобактерии \\
17 & Тенерикуты \\
Эрипсипелотрихи \\
П р и м е ч н и е. ОТЕ - оперативно-таксономические единицы. Лактобациллы (ОТЕ № 2), \\
условно патогенные энтеробактерии (ОТЕ № 9) и актиномицеты (ОТЕ № 10) - индикаторные \\
группы микроорганизмов, по которым оценивается переваримость кормов и защищенность птицы \\
от патогенов. \\
\hline
\end{tabular}

В таблице 2 представлены таксономические группы микроорганизмов, которые присутствуют в полученных нами профилях ОТЕ микробиоты кишечника у цыплят-бройлеров.

Методика фрактального анализа профилей ОTЕ. С точки зрения минимизации энергетических и ресурсных затрат выгоднее разлагать растительные субстраты несколькими микробными генотипами, объединенными в биосистему. Этим обеспечивается своевременная и достаточная по интенсивности генерация микроорганизмами ферментативных потоков для деструкции растительных субстратов. При этом и количество ферментов, и численность микробных генотипов, генерирующих ферменты, предположительно будет находиться в однозначном соответствии с числом целевых сайтов рестрикции в разлагаемых органических молекулах. Поэтому в оптимизированной деструктивной биосистеме должны быть одинаковые соотношения между численностями (частотами) биосистемных микробных генотипов и численностями (частотами) целевых сайтов рестрикции в органических молекулах. Это означает, что в оптимальных микробных биосистемах частоты генотипов и частоты ОTЕ в профилях ОТЕ, как и сайты рестрикции в разлагаемых органических молекулах, должны описываться фундаментальными фрактальными степенными соотношениями. На основании этого утверждения было сформулировано определение элементарного фрактала ОТЕ и проведен фрактальный анализ профилей ОТЕ.

Oпределение элементарного фрактала ОTЕ. Если три частоты ОТЕ образуют геометрическую числовую последовательность, например $\{0,5 ; 0,25 ; 0,125\}$, или в логарифмическом виде арифметическую числовую 
последовательность $\left\{\log _{2}(0,5)=-1 ; \log _{2}(0,25)=-2 ; \log _{2}(0,125)=-3\right\}$, то эти ОТЕ представляют собой элементарный фрактал ОТЕ, а соответствующие микробные генотипы принадлежат биосистемной части микробиоты. При этом допускается объединение нескольких элементарных фракталов ОТЕ в более крупный по численности мегафрактал ОТЕ.

Мегафракталы ОТЕ дают представление о генотипическом составе микробных биосистем микробиоты кишечников птиц и о числе микробных генотипов, развивающихся по индивидуальным стратегиям вне биосистемы. Отношение фрактальных и внефрактальных ОТЕ характеризует масштабы использования микробного ресурса при преобразовательной биохимической деятельности микрофлоры птиц. Мы предполагаем, что снижение числа ОТЕ в мегафракталах ОТЕ, а значит, и генотипов в микробных биосистемах сигнализирует о снижении производительности биохимических преобразований в кишечнике птиц и, как следствие, о задержке их развития.

Фрактальный портрет профиля ОТЕ. Для визуального обнаружения мегафракталов ОТЕ и их математического учета можно воспользоваться фрактальным портретом профиля ОТЕ. Построение фрактальных портретов ОТЕ значительно облегчает обнаружение элементарных фракталов ОТЕ.

3. Ранжированные по убыванию частоты ОТЕ по группам цыплят-бройлеров кросса Смена, получавших экспериментальные пробиотические препараты $(n=25$, СГЦ «Загорское ЭПХ», Московская обл., 2018 год)

\begin{tabular}{|c|c|c|c|c|c|}
\hline \multicolumn{6}{|c|}{ Группа } \\
\hline \multicolumn{2}{|c|}{$1 \mathrm{~K}$} & \multicolumn{2}{|c|}{20} & \multicolumn{2}{|c|}{30} \\
\hline № OTE & частота, \% & № OTE & частота, \% & № OTE & частота, \% \\
\hline 6 & 26,7 & 5 & 39,4 & 5 & 31,7 \\
\hline 7 & 25,3 & 6 & 20,8 & 6 & 22,3 \\
\hline 5 & 24,5 & 7 & 19,3 & 7 & 19,3 \\
\hline 17 & 14,8 & 17 & 13,8 & 17 & 13,6 \\
\hline 2 & 3,2 & 2 & 2,3 & 2 & 4,1 \\
\hline 14 & 2,0 & 4 & 1,2 & 14 & 3,2 \\
\hline 4 & 1,8 & 14 & 1,2 & 9 & 1,3 \\
\hline 10 & 0,6 & 10 & 0,6 & 4 & 1,0 \\
\hline 16 & 0,5 & 3 & 0,4 & 1 & 0,9 \\
\hline 9 & 0,4 & 16 & 0,3 & 10 & 0,8 \\
\hline 8 & 0,2 & 8 & 0,2 & 13 & 0,4 \\
\hline & & 9 & 0,2 & 16 & 0,4 \\
\hline & & 15 & 0,2 & 11 & 0,3 \\
\hline & & 1 & 0,1 & 15 & 0,3 \\
\hline & & & & 3 & 0,2 \\
\hline & & & & 8 & 0,1 \\
\hline & & & & 12 & 0,1 \\
\hline
\end{tabular}

Пр и м е ч а н и е. ОТЕ - оперативно-таксономические единицы. Номера ОТЕ соответствуют номерам ОТЕ в таблице 2. 1 к - контрольная, 20, 3o - две опытные группы бройлеров. В группе 2о к ОР добавляли пробиотик № 1, содержащий Lactobacillus plantarum $\left(10^{7} \mathrm{KOE} / \Gamma\right)$, в $30-$ пробиотик № 2, содержащий Lactobacillus fermentum $\left(10^{7} \mathrm{KOE} / г\right)$ (дозы препаратов -1 кг/т корма).

Перед построением фрактального портрета нужно упорядочить профиль ОТЕ по убыванию значений частот (табл. 3). Это необходимо, чтобы определить ОТЕ с максимальной частотой (рmax), то есть ОТЕ, занявшее первое место в упорядоченном профиле ОТЕ. После этого процедура построения фрактального портрета профиля ОТЕ будет сводиться к размещению на координатной плоскости точек (или любых геометрических фигур), представляющих своим положением на портрете каждую ОТЕ. Для определения положения на портрете каждой ОТЕ (каждой точки ОТЕ) необходимо вычислить их Y- и X-координаты по следующим формулам:

$$
\mathrm{Y}_{i}=\log _{2}\left(\mathrm{p}_{i} / \mathrm{p}_{\max }\right), \mathrm{X}_{i}=\text { дробная часть } \log _{2}\left(\mathrm{p}_{i} / \mathrm{p}_{\max }\right),
$$

где $\mathrm{p}_{i}-$ частота ОТЕ с порядковым номером ( $\left.i\right)$ в профиле ОТЕ (табл. 3 ). 
В соответствии с формулами [1] и данными таблицы 3 нами были вычислены координаты точек ОТЕ и построены фрактальные портреты профилей ОТЕ для кишечной микробиоты трех групп исследуемых бройлеров (рис.).

На фрактальных портретах (см. рис.) некоторые точки соединены отрезками прямых линий. Этим способом не портретах выделяются элементарные фракталы ОТЕ, что не противоречит определению элементарного фрактала ОТЕ. Например, логарифмы частот ОТЕ №№ 3, 9, 1 (см. рис., Б) образуют арифметический ряд $\{-6,62 ;-7,62 ;-8,62\}$. Поэтому они представляют элементарный фрактал ОТЕ и на портрете должны быть соединены отрезком прямой линии. По аналогичным причинам выделены отрезками прямых линий элементарные фракталы ОТЕ: ОТЕ №№ 4, 10, 8 (см. рис., А) - ряд логарифмов частот $\{-3,89 ;-5,48 ;-7,06\}$; ОТЕ №№ 10 , $13,3,8$ (см. рис., В) - ряд логарифмов частот $\{-5,31 ;-6,31 ;-7,31 ;-8,31\}$ и др. На портретах, представленных на рисунке А и В, элементарные фракталы ОТЕ объединились в один мегафрактал ОТЕ, а на портрете на рисунке Б - в два мегафрактала ОТЕ.

A

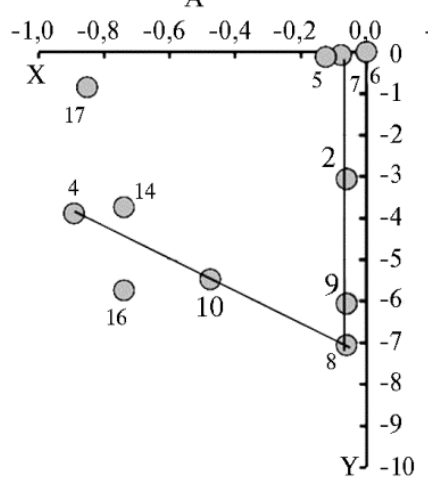

Б

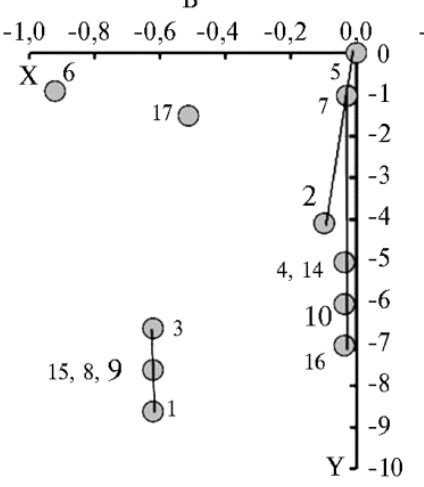

B

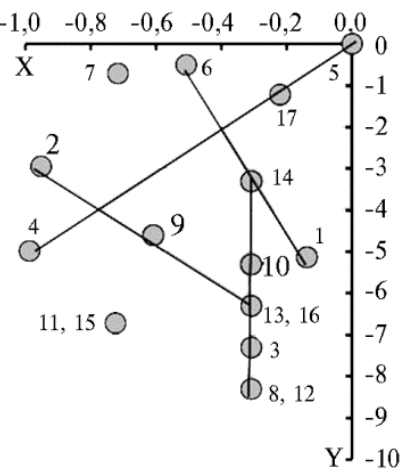

Фрактальные портреты профилей оперативно-таксономических единиц (ОТЕ) микробиоты кишечника в трех группах 36-суточных цыплят-бройлеров кросса Смена, получавших экспериментальные пробиотические препараты: А - контрольная группа (1к, основной рацион $-\mathrm{OP}, \mathrm{cm}$. табл. 1); Б - опытная группа 2о (ОР + пробиотик № 1, содержащий Lactobacillus plantarum, В - опытная группа 3о (ОР + пробиотик № 2, содержащий Lactobacillus fermentum) $(n=25$, СГЦ «Загорское ЭПХ», Московская обл., 2018 год).

Y- и Х-координаты точек, изображающих ОТЕ, вычислялись по формулам [1]. Цифры вблизи кружков соответствуют номерам ОТЕ из таблицы 2. Номера лактобактерий (ОТЕ № 2) и условно-патогенных энтеробактерий (ОТЕ № 9) и актиномицетов (ОТЕ № 10) специально увеличены, так как это индикаторные группы микроорганизмов, по которым оценивается переваримость кормов и защищенность птицы от патогенов. Отрезки прямых линий, соединяющие точки, выделяют элементарные фракталы ОТЕ.

Индекс биоконсолидации микробиоты. Фрактальные портреты профилей ОТЕ (рис.) представляют различные по генотипическому и количественному составу мегафракталы ОТЕ. Мы полагаем, что число ОТЕ в составе мегафракталов ОТЕ (а значит, и число генотипов в составе микробной биосистемы) представляет интенсивность биохимических преобразований органических субстратов в кишечниках птиц, выполняемых биосистемной частью микробиоты. Следовательно, чем больше микробных генотипов из микробиоты участвуют в биосистемных биохимических преобразованиях растительного субстрата, тем эффективнее и в больших масштабах осуществляются эти преобразования, и больше питательных веществ получает макроорганизм. Поэтому индекс биоконсолидации микробиоты кишечника 
бройлеров Ind мы определяем, как отношение числа ОТЕ в составе мегафрактала ОТЕ к общему числу ОТЕ в профилях ОТЕ:

$$
\text { Ind }=\mathrm{N}_{\mathrm{F}} / \mathrm{N}_{0} \text {, }
$$

где $\mathrm{N}_{\mathrm{F}}, \mathrm{N}_{0}-$ соответственно число ОТЕ в мегафракталах ОТЕ и общее число ОТЕ в профилях ОТЕ.

Результаты вычисления индекса биоконсолидации микробиоты кишечника в наблюдаемых группах бройлеров приведены в таблице 4.

4. Средняя живая масса и индекс биоконсолидации микробиоты у 36-суточных цыплят-бройлеров кросса Смена, получавших экспериментальные пробиотические препараты $(n=25$, СГЦ «Загорское ЭПХ», Московская обл., 2018 год)

\begin{tabular}{|c|c|c|c|}
\hline \multirow{2}{*}{ Показатель } & \multicolumn{3}{|c|}{ Группа } \\
\hline & $1 \mathrm{~K}$ & 20 & 30 \\
\hline Средняя масса, кг & $2,15 \pm 0,02$ & $2,05 \pm 0,02$ & $2,14 \pm 0,02$ \\
\hline Индекс биоконсолидации микробиоты Ind & $0,55 \pm 0,02$ & $0,86 \pm 0,02$ & $0,82 \pm 0,02$ \\
\hline
\end{tabular}

Обсуждение результатов исследования. Фрактальный анализ частотно-таксономических профилей ОТЕ микробиоты кишечника бройлеров на выходе предоставляет информацию о размерах мегафракталов ОТЕ и о числе микробных генотипов в кишечниках птиц, объединившихся в биосистему. Индекс биоконсолидации микробиоты (Ind) рассчитывается, как отношение числа ОТЕ в мегафракталах ОТЕ к общему количеству ОТЕ в частотно-таксономических профилях микробиоты кишечника птиц. Равенство единице индекса биоконсолидации микробиоты (Ind $=1)$ означает, что все генотипы микробиоты принимают участие в совместных преобразовательных биосистемных процессах, а равенство нулю (Ind $=0)-$ отсутствие биосистемной организации микробиоты в кишечнике бройлеров. На основании фрактального анализа частотно-таксономических профилей ОТЕ было установлено, что у бройлеров из опытных групп значение индекса биоконсолидации микробиоты (Ind $=0,86$ в группе 2o, Ind $=0,82$ в группе 3о) превышает значение индекса биоконсолидации микробиоты у контрольной группы птиц (группа $1 \mathrm{~K}-$ Ind $=0,55)$. Это означает, что применение бактерий L. plantarum и L. fermentum в качестве пробиотиков способствует лучшей самоорганизации микробиоты кишечника птицы.

Однако средние массы бройлеров в контрольной и опытных группах (см. табл. 4) не коррелируют со значениями индексов биоконсолидации их микробиоты. Кроме этого, средняя масса бройлеров в опытной группе 2о $(2,05 \pm 0,02$ кг) оказалась даже меньше, чем средняя масса бройлеров в контрольной группе 1к $(2,15 \pm 0,02$ кг). Возможно, это есть следствие неудачной самоорганизации микробных биосистем в кишечнике птицы из группы 2о, что было спровоцировано применением пробиотика № 1. В отличие от фрактального портрета Б (см. рис.) на портретах А и В (см. рис.) присутствует по одному мегафракталу ОТЕ. Кроме этого, обращает на себя внимание тот факт, что в двух несвязанных мегафракталах ОТЕ (см. рис., Б) оказались разъединенными индикаторные ОТЕ №№ 2, 9, 10 (лактобациллы, энтеробактерии и актиномицеты), а на фрактальных портретах А и В (см. рис.) эти индикаторные ОТЕ присутствуют в одном мегафрактале ОТЕ. Возможно, расположение индикаторных ОТЕ в разных мегафракталах OTE, а значит, и расположение индикаторных генотипов в разных биосистемах сказываются на снижении эффективности преобразования органических субстратов и задержке развития бройлеров в группе 20. 
Таким образом, нами предложена методики фрактального анализа частотно-таксономических профилей оперативных таксономических единиц (ОТЕ) микробиоты кишечника у птиц для оценки влияния кормовых факторов на биосистемную самоорганизацию микрофлоры и эффективность биохимических преобразований растительных субстратов. На основании вычисленного индекса биоконсолидации микробиоты кишечника у бройлеров, выращиваемых на рационах с добавлением разных экспериментальных пробиотиков, для применения в составе таких препаратов рекомендуется Lactobacillus fermentum, так как эти бактерии способствуют лучшей самоорганизации микроорганизмов в деструктивные биосистемы, полноценному развитию птиц и снижению их заболеваемости.

\title{
1 ФГБНУ Всероссийский НИИ сельскохозяйственной П Поступила в редакцию микробиологии 5 декабря 2019 года
}

196608 Россия, г. Санкт-Петербург-Пушкин, ш. Подбельского, 3

e-mail: Nik.IvanVorobyov@yandex.ru $\square$;

2ФНЦ Всероссийский научно-исследовательский

и технологический институт птицеводства РАН,

141311 Россия, Московская обл., г. Сергиев Посад, ул. Птицеградская, 10,

e-mail: Olga@vnitip.ru, dissovet@vnitip.ru;

ЗФГБОУ ВО Московская государственная академия

ветеринарной медицины и биотехнологии

МВА им. К.И. Скрябина,

109472 Россия, г. Москва, ул. Академика Скрябина, 23,

e-mail: zoo-kafedra@yandex.ru, ilnikonov@yandex.ru

Sel'skokhozyaistvennaya biologiya [Agricultural Biology], 2021, V. 56, № 2, pp. 400-410

\section{FRACTAL ANALYSIS OF FREQUENCY-TAXONOMIC PROFILE OF BROILER'S GUT MICROBIOTA FOR STUDYING THE INFLUENCE OF PROBIOTICS ON BIRD DEVELOPMENT}

\author{
N.I. Vorobyov ${ }^{1}$, I.A. Egorov ${ }^{2}$, I.I. Kochish ${ }^{3}$, I.N. Nikonov ${ }^{3}$, T.N. Lenkova ${ }^{2}$
}

\begin{abstract}
${ }^{1}$ All-Russian Research Institute for Agricultural Microbiology, 3, sh. Podbel'skogo, St. Petersburg, 196608 Russia, e-mail Nik.IvanVorobyov@yandex.ru ( $\square$ corresponding author);

${ }^{2}$ Federal Scientific Center All-Russian Research and Technological Poultry Institute RAS, 10, ul. Ptitsegradskaya, Sergiev Posad, Moscow Province, 141311 Russia, e-mail Olga@vnitip.ru, dissovet@vnitip.ru;

${ }^{3}$ Skryabin Moscow State Academy of Veterinary Medicine and Biotechnology, 23, ul. Akademika K.I. Skryabina, Moscow, 109472 Russia, e-mail zoo-kafedra@yandex.ru, ilnikonov@yandex.ru

ORCID:

Vorobyov N.I. orcid.org/0000-0001-8300-2287

Egorov I.A. orcid.org/0000-0001-9122-9553

Kochish I.I. orcid.org/0000-0001-8892-9858

The authors declare no conflict of interests

Acknowledgements:

The study was carried out on the basis of the Federal Scientific Center All-Russian Research and Technological Poultry Institute RAS.

Supported financially by the Russian Science Foundation grant for the project No. 16-16-04089-P "Studying the physiological and microbiological characteristics of the digestion of chicken meat in the embryonic and postembryonic periods to create new feeding technologies that provide the fullest realization of the genetic potential of the bird"

Received December 5, 2019

doi: 10.15389/agrobiology.2021.2.400eng
\end{abstract}

\section{Abstract}

The article provides theoretical and empirical data about the probiotic effect on the microbiota bioconsolidation in the broiler intestines of the Smena cross. The results of such studies can be used to improve the quality and volume of meat products in large-scale production. The probiotics have been used to improve feed digestibility and accelerate bird development. To stimulate the transformation of plant substrates in the bird intestines, probiotics were used instead of antibiotics. The probiotics contained the bacteria Lactobacillus plantarum and Lactobacillus fermentum. The study goal is to develop a methodology for fractal analysis of the frequency-taxonomic profiles of operational taxonomic units (OTUs) of the microbiota into the bird intestines. Using the fractal methodology, the 
index of microbiom bioconsolidation of the bird intestines was calculated, which characterizes the biosystem self-organization of microflora and the efficiency of biochemical transformations of plant substrates in the bird intestines. In the experiment, the microflora was studied in one control and two experimental groups of birds. The OTUs profiles were obtained by the molecular genetic NGS method (Next Generation Sequencing). The key concept of fractal analysis of OTUs profiles was the concept of the elementary OTU fractal. The elementary OTU fractal is three OTUs, the frequencies of which form a geometric numerical sequence (for example, $\{0.5 ; 0.25 ; 0.125\}$ ). The OTU profiles may contain several elementary OTU fractals combined into one larger OTU megafractal. We assume that if the number of OTUs combined into the OTU megafractal increases, then biochemical transformations of plant substrate are carried out more efficiently and on a large scale, and the bird macroorganism receives more nutrients. Therefore, we define the bioconsolidation index of the broiler microbiome as the ratio of the number of OTUs in the OTU megafractal to the total number of OTUs in the OTU profiles. The fractal portraits of OTU profiles were used to identify elementary OTU fractals. The elementary OTU fractals were identified by the linear arrangement of three OTU images on fractal portrait. The fractal analysis confirmed that the bacterial probiotics increase the microbiom bioconsolidation in the bird intestines. The microbiome bioconsolidation index in the experimental groups of birds $(0.82 \ldots 0.86)$ was higher than this index in the control group of birds $(0.55)$. According to the results of fractal analysis, probiotic No. 1 (with Lactobacillus plantarum) is not recommended for use, and probiotic No. 2 (with Lactobacillus fermentum) is recommended for use.

Keywords: frequency-taxonomic profile, fractal portrait, intestinal microbiota, biosystem consolidation index, broilers, dietary probiotics, Lactobacillus.

\section{R E F E R E N C E S}

1. Torok V.A., Hughes R.J., Mikkelsen L.L., Perez-Maldonado R., Balding K., MacAlpine R., Percy N.J., Ophel-Keller K. Identification and characterization of potential performance-related gut microbiotas in broiler chickens across various feeding trials. Applied and Environmental Microbiology, 2011, 77(17): 5868-5878 (doi: 10.1128/AEM.00165-11).

2. Sun H., Tang J.-W., Yao X.-H., Wu Y.-F., Wang X., Feng J. Effects of dietary inclusion of fermented cottonseed meal on growth, cecal microbial population, small intestinal morphology, and digestive enzyme activity of broilers. Trop. Anim. Health Prod., 2013, 45: 987-993 (doi: 10.1007/s11250-012-0322-y).

3. Stanley D., Denman S.E., Hughes R.J., Geier M.S., Crowley T.M., Chen H., Haring V.R., Moore R.J. Intestinal microbiota associated with differential feed conversion efficiency in chickens. Appl. Microbiol. Biotechnol., 2012, 96: 1361-1369 (doi: 10.1007/s00253-011-3847-5).

4. Brisbin J.T., Gong J., Orouji S., Esufali J., Mallick A.I., Parvizi P., Shewen P.E., Sharif S. Oral treatment of chickens with lactobacilli influences elicitation of immune responses. Clin. Vaccine Immunol., 2011, 18(9): 1447-1455 (doi: 10.1128/CVI.05100-11).

5. Biggs P., Parsons C.M., Fahey G.C. The effects of several oligosaccharides on growth performance, nutrient digestibilities, and cecal microbial populations in young chicks. Poultry Science, 2007, 86(11): 2327-2336 (doi: 10.3382/ps.2007-00427).

6. Chichlowski M., Croom J., McBride B.W., Daniel L., Davis G., Koci M.D. Direct-fed microbial PrimaLac and Salinomycin modulate whole-body and intestinal oxygen consumption and intestinal mucosal cytokine production in the broiler chick. Poultry Science, 2007, 86(6): 1100-1106 (doi: 10.1093/ps/86.6.1100).

7. Peng W.-X., Marchal J.L.M., van der Poel A.F.B. Strategies to prevent and reduce mycotoxins for compound feed manufacturing. Animal Feed Science and Technology, 2018, 237: 129-153 (doi: 10.1016/j.anifeedsci.2018.01.017).

8. Stanley D., Hughes R.G., Moore R. Microbiota of chicken gastrointestinal tract: influence on health productivity and disease. Applied Microbiology and Biotechnology, 2014, 98(10): 4301-4310 (doi: 10.1007/s00253-014-5646-2).

9. Surai P.F. Polyphenol compounds in the chicken/animal diet: from the past to the future. Journal of Animal Physiology and Animal Nutrition, 2014, 98(1): 19-31 (doi: 10.1111/jpn.12070).

10. Yang Ch., Chowdhury M.A.K., Hou Y., Gong J. Phytogenic compounds as alternatives to infeed antibiotics: potentials and challenges in application. Pathogens, 2015, 4(1): 137-156 (doi: $10.3390 /$ pathogens4010137).

11. Jamroz D., Wiliczkiewicz A., Wertelecki T., Orda J., Skorupińska J. Use of active substances of plant origin in chicken diets based on maize and locally grown cereals. British Poultry Science, 2005, 46(4): 485-493 (doi: 10.1080/00071660500191056).

12. Vorob'ev N.I., Sviridova O.V., Popov A.A., Rusakova I.V., Petrov V.B. Graph-analysis in genemetabolic networks of soil microorganisms which transformed plant residues to humus substances Sel'skokhozyaistvennaya biologiya, 2011, 3: 88-93 (in Russ.).

13. Fisinin V.I., Il'ina L.A., Iyldyrym E.A., Nikonov I.N., Filippova V.A., Laptev G.Yu., Novikova N.I., Grozina A.A., Lenkova T.N., Manukyan V.A., Egorov I.A. Mikrobiologiya, 2016, 85(4): 
472-480 (doi: 10.7868/S0026365616040054) (in Russ.).

14. Li J., Hao H., Cheng G., Liu C., Ahmed S., Shabbir M.A.B., Hussain H.I., Dai M., Yuan Z. Microbial shifts in the intestinal microbiota of Salmonella infected chickens in response to enrofloxacin. Frontiers in Microbiology, 2017, 8: 1711 (doi: 10.3389/fmicb.2017.01711).

15. Wei S., Morrison M., Yu Z. Bacterial census of poultry intestinal microbiome. Poultry Science, 2013, 92(3): 671-683 (doi: 10.3382/ps.2012-02822).

16. Pielsticker C., Glonder G., Rautenschlein S. Colonization properties of Campylobacter jejuni in chickens. European Journal of Microbiology and Immunology, 2012, 2(1): 61-65 (doi: 10.1556/EuJMI.2.2012.1.9).

17. Lan Y., Verstegen M.W.A., Tamminga S., Williams B.A. The role of the commensal gut microbial community in broiler chickens. World's Poultry Science Journal, 2005, 61(1): 95-104 (doi: 10.1079/WPS200445).

18. Wang Y., Sun J., Zhong H., Li N., Xu H., Zhu Q., Liu Y. Effect of probiotics on the meat flavour and gut microbiota of chicken. Scientific Reports, 2017, 7: 6400 (doi: 10.1038/s41598-01706677-z).

19. Lu J., Idris U., Harmon B., Hofacre C., Maurer J.J., Lee M.D. Diversity and succession of the intestinal bacterial community of the maturing broiler chicken. Applied and Environmental Microbiology, 2003, 69(11): 6816-6824 (doi: 10.1128/AEM.69.11.6816-6824.2003).

20. Liao N., Yin Y., Sun G., Xiang C., Liu D., Yu H.D., Wang X. Colonization and distribution of segmented filamentous bacteria (SFB) in chicken gastrointestinal tract and their relationship with host immunity. FEMS Microbiology Ecology, 2012, 81(2): 395-406 (doi: 10.1111/j.15746941.2012.01362.x).

21. Bjerrum L., Engberg R.M., Leser T.D., Jensen B.B., Finster K., Pedersen K. Microbial community composition of the ileum and cecum of broiler chickens as revealed by molecular and cellularbased techniques. Poultry Science, 2006, 85(7): 1151-1164 (doi: 10.1093/ps/85.7.1151).

22. Louis P., Young P., Holtrop G., Flint H.J. Diversity of human colonic butyrate-producing bacteria revealed by analysis of the butyryl-CoA:acetate CoA-transferase gene. Environmental Microbiology, 2010, 12(2): 304-314 (doi: 10.1111/j.1462-2920.2009.02066.x).

23. Niba A.T., Beal J.D., Kudi A.C., Brooks P.H. Bacterial fermentation in the gastrointestinal tract of non-ruminants: influence of fermented feeds and fermentable carbohydrates. Tropical Animal Health and Production, 2009, 41(7): 1393-1407 (doi: 10.1007/s11250-009-9327-6).

24. Bogatykh B.A. Fraktal'naya priroda zhivogo: sistemnoe issledovanie biologicheskoi evolyutsii i priroda soznaniya. Moscow, 2012 [Fractal nature of living things: systemic study of biological evolution and nature of consciousness] (in Russ.).

25. Shreder M. Fraktaly, khaos, stepennye ryady. Izhevsk, 2001 [Fractals, chaos, power series] (in Russ.).

26. Il'ina L.A., Iyldyrym E.A., Nikonov I.N., Filippova V.A., Laptev G.Yu., Novikova N.I., Grozina A.A., Lenkova T.N., Manukyan V.A., Fisinin V.I., Egorov I.A. Taxons of chicken cecum microbiom are abundant, and influenced by the combined feed composition and decreased metabolizable energy. Agricultural Biology [Sel'skokhozyaistvennaya biologiya], 2015, 50(6): 817824 (doi: 10.15389/agrobiology.2015.6.817eng).

27. Sviridova O.V., Vorobyov N.I., Provorov N.A., Orlova O.V., Rusakova I.V., Andronov E.E., Pishchik V.N., Popov A.A., Kruglov Yu.V. The alignment of soil's conditions for plant's development during microbial destruction of plant's residues by microbial preparations. Agricultural Biology [Sel'skokhozyaistvennaya biologiya], 2016, 51(5): 664-672 (doi: 10.15389/agrobiology.2016.5.664rus).

28. Orlova O.V., Andronov E.E., Vorobyov N.I., Kolodyazhnyi A.Yu., Moskalevskaya Yu.P., Patyka N.V., Sviridova O.V. Composition and functioning of microbial communities in the decomposition of straw cereals in sod podzolic soil. Agricultural Biology [Sel'skokhozyaistvennaya biologiya], 2015, 50(3): 305-314 (doi: 10.15389/agrobiology.2015.3.305rus). 